\title{
Produtividade de cultivares de morangueiro, submetidas a diferentes épocas de plantio
}

Wilson R Pereira ${ }^{1}$; Rovilson J de Souza ${ }^{2}$; Jony E Yuri ${ }^{3}$; Sindynara Ferreira ${ }^{1}$

${ }^{1}$ IFSULDEMINAS, Depto. Produção Vegetal, Praça Tiradentes 416, 37576-000 Inconfidentes-MG; wrpufla@yahoo.com.br; sindynaraferreira@yahoo.com.br; ${ }^{2}$ UFLA, Depto. Agricultura, C. Postal 37, 37200-000 Lavras-MG; rovilson@ufla.com.br; ${ }^{3}$ Embrapa

Semiarido, C. Postal 23, 56302-970 Petrolina-PE; jonyyuri@uol.com.br

\section{RESUMO}

O objetivo foi avaliar a produtividade de cultivares de morangueiro, em diferentes épocas de plantio. O experimento foi conduzido em Bom Repouso, sul de Minas Gerais. Utilizou-se o delineamento de blocos casualizados com cinco repetições, em esquema de parcelas subdivididas, envolvendo quatro cultivares (Aromas, Camarosa, Festival e Oso Grande) e quatro épocas de plantio (maio, junho, julho e agosto), no espaçamento de $35 \times 35 \mathrm{~cm}$. O plantio em maio proporcionou a melhor opção, exceto para 'Oso Grande' em que não houve diferença entre maio, junho e julho; já o plantio em agosto apresentou resultado inferior. Quanto às cultivares, Aromas esteve entre as mais produtivas em maio e agosto, enquanto que Oso Grande teve esse desempenho em todas as épocas estudadas. Para a característica de massa de frutos comerciais o comportamento das cultivares foi o mesmo observado para o número de frutos comerciais. Para frutos não comerciais e massa de frutos não comerciais não houve interação significativa entre os fatores estudados, sendo que 'Aromas' e 'Oso Grande' apresentaram resultados inferiores, o que é vantajoso. 'Oso Grande' proporcionou maior número de frutos comerciais, sendo assim considerada neste trabalho a cultivar que mais se adaptou para os plantios em Bom Repouso.

Palavras-chave: Fragaria x ananassa, produção, adaptação.

\begin{abstract}
Yield of strawberry cultivars submitted to different planting dates

We evaluated strawberry yield in different planting dates. The experiment was carried out in Bom Repouso, southern Minas Gerais state, Brazil. A randomized block design with five replications in a factorial design was used, comprising four cultivars (Aromas, Camarosa, Festival and Oso Grande) and four planting dates (May, June, July and August), in a spacing of $35 \times 35 \mathrm{~cm}$. Planting on May was the best option, except for 'Oso Grande' with no difference among May, June and July, the result being inferior in August. Regarding the cultivars, 'Aromas' was among the most productive in May and August, while 'Oso Grande' kept its productivity throughout the studied seasons. The cultivars presented the same characteristic for marketable fruits number and mass. There was no interaction between number and mass of no marketable fruits, in which 'Aromas' and 'Oso Grande' presented inferior results, considered advantageous. 'Oso Grande' produced the highest number of marketable fruits and was considered, in this study, the cultivar most adapted for the planting seasons in Bom Repouso.
\end{abstract}

Keywords: Fragaria $x$ ananassa, production, adaptation.

\section{(Recebido para publicação em 6 de fevereiro de 2012; aceito em 16 de agosto de 2013) (Received on February 6, 2012; accepted on August 16, 2013)}

$\mathrm{O}$ morangueiro (Fragaria $x$ ananassa) representa uma cultura de considerável expressão econômica para produtores brasileiros, tendo grande destaque em estados como Minas Gerais, Rio Grande do Sul, São Paulo e Espírito Santo. A produção nestes estados se concentra em regiões específicas, principalmente com relação às características climáticas, exigidas pela planta para o seu desenvolvimento pleno (Assis, 2004). No estado de Minas Gerais, o morangueiro é produzido na maioria dos municípios do extremo Sul, na região da Mantiqueira, sendo Pouso Alegre e Estiva os maiores produtores, e nos Campos das Vertentes, em Barbacena e municípios vizinhos (Filgueira,
2000). O sul de Minas responde por $95 \%$ de toda produção estadual, o que corresponde a uma produção anual de aproximadamente $85 \mathrm{mil}$ toneladas (Scicco, 2010). Dentre os principais fatores que proporcionaram destaque ao sul de Minas Gerais, estão as condições climáticas favoráveis para o cultivo e, também, a localização estratégica, próxima aos grandes centros consumidores (Veiga Junior, 2006).

Trata-se de uma planta muito sensível às condições climáticas. Assim, uma cultivar que produza bem numa determinada região poderá não se adaptar em outra, produzir menos ou ser mais afetada por pragas ou doenças. A melhor época de plantio varia para cada região e, também, depende da cultivar (Bernardini et al., 2005). Até o início dos anos 2000, utilizavam-se no Brasil principalmente as cultivares de dias curtos (Assis, 2004). Assim, a produção se concentrava entre os meses de maio e dezembro, provocando um período com pouca oferta de morango, nos demais meses.

Atualmente, com a introdução de novas cultivares com características de dias neutros, tem se tornado possível a produção de morango nos períodos considerados como entressafra, com a possibilidade de se realizar o início de cultivo fora da época considerada tradicional. No entanto, verifica-se a necessidade de realização de traba- 
lhos de pesquisas visando avaliar as melhores cultivares que apresentem as características de dias neutros, e adequar para as mesmas, as melhores épocas de transplantio das mudas, de acordo com a região produtora.

A cultura vem passando por uma evolução tecnológica muito significativa, tanto em relação ao incremento de produtividade, como em relação à diminuição do custo de produção, sendo que também é importante mencionar a pesquisa, e o sistema de plantio integrado que ultimamente vem aumentando ano a ano, em uma cultura que abrange um grande contingente de mão-de-obra. O morango apresenta uma importância social e econômica muito grande, sendo geradora de emprego e renda para as comunidades envolvidas (Antunes et al., 2007).

O uso de cultivares adaptadas para cada região constitui-se em importante fator para o sucesso na produção. A seleção dessas cultivares deve ser baseada na produtividade, resistência a pragas, aceitação no mercado e produção na entressafra, visando aumento na lucratividade (Rebelo \& Balardin, 1997; Botelho, 1999).

$\mathrm{Na}$ região de Pouso Alegre-MG, Dias et al. (2009) observaram que a cultivar Palomar, embora tenha produzido menor número de frutos, apresentou quantidade de frutos comerciais superior à 'Camarosa' e frutos com massa média superior a 'Camarosa' e 'Oso Grande', sendo estas duas as principais cultivares para essa região. Entretanto, 'Camarosa' destacou-se das demais pelo desempenho produtivo apresentado na região, fato também observado por Duarte Filho (2006) em ensaios realizados em Caldas-MG, onde a cultivar apresentou maior número de frutos.

$\mathrm{Na}$ maioria dos municípios produtores de morango no sul de Minas Gerais, o plantio inicia-se no final do mês de fevereiro. Dentro deste contexto o presente trabalho objetivou avaliar o potencial produtivo de cultivares de morangueiro transplantadas em diferentes épocas, buscando assim alternativas para que a cultura seja estendida para outros meses do ano, aproveitando as condições edafoclimáticas da região sul do estado de Minas Gerais.

\section{MATERIAL E MÉTODOS}

$\mathrm{O}$ experimento foi conduzido em campo de produção comercial, localizado no município de Bom Repouso, sul de Minas Gerais (22 $28^{\prime} 16^{\prime} ' \mathrm{~S}$, $46^{\circ} 08^{\prime} 42^{\prime}$ 'O, altitude de $1.375 \mathrm{~m}$ ), de maio de 2007 a fevereiro de 2008. O clima da região, segundo a classificação de Köppen, é do tipo Cwa, com característica de $\mathrm{Cwb}$; a precipitação média anual é de $1.500 \mathrm{~mm}$, e a média durante o período da realização do experimento foi de $1.170 \mathrm{~mm}$, as temperaturas médias mensal máxima, média e mínima foram 22,15 e $10^{\circ} \mathrm{C}$.

Uma amostra do solo da área, originalmente classificado como Latossolo Vermelho Distroférrico, de textura média, foi analisada em laboratório e, sua análise química resultou $\mathrm{pH}$ (em água $)=$ 4,$9 ; \mathrm{MO}=21,7 \mathrm{~g} / \mathrm{dm}^{3} ; \mathrm{P}=43 \mathrm{mg} / \mathrm{dm}^{3}$; $\mathrm{K}=86 \mathrm{mg} / \mathrm{dm}^{3} ; \mathrm{Ca}=1,80 \mathrm{cmol}_{\mathrm{c}} / \mathrm{dm}^{3}$; $\mathrm{Mg}=0,40 \mathrm{cmol}_{\mathrm{c}} / \mathrm{dm}^{3} ; \mathrm{Al}=0,30 \mathrm{cmol}_{\mathrm{c}} /$ $\mathrm{dm}^{3} ; \mathrm{H}=4,0 \mathrm{cmol}_{\mathrm{c}} / \mathrm{dm}^{3} ; \mathrm{V}=22,4 \%$. Realizou-se a calagem com objetivo de atingir $80 \%$ de saturação por bases, segundo as recomendações da Comissão de Fertilidade do solo de Minas Gerais, 5 aproximação (Ribeiro et al., 1999). Foi aplicado o calcário na proporção de 3,4 t/ha. Em seguida, na véspera de cada época de transplantio (de acordo com o tratamento) a adubação de base foi realizada utilizando a proporção de $300 \mathrm{~kg} / \mathrm{ha}$ de $\mathrm{P}_{2} \mathrm{O}_{5}, 100 \mathrm{~kg} / \mathrm{ha}$ de $\mathrm{K}_{2} 0$ e $40 \mathrm{~kg} / \mathrm{ha}$ de N. Da mesma forma, seguindo critérios desses autores, foram realizadas adubações de cobertura. $\mathrm{O}$ experimento foi conduzido em cultivo protegido usando túnel baixo de polietileno aditivado de $100 \mu \mathrm{m}$ de espessura contendo 1,20 $\mathrm{m}$ de altura por 1,20 $\mathrm{m}$ de largura e a irrigação foi realizada pelo sistema de gotejo.

$\mathrm{O}$ delineamento experimental foi em blocos ao acaso, em esquema de parcelas subdivididas, constituindo as parcelas principais as épocas de transplantio (maio, junho, julho e agosto) e as cultivares (Aromas, Camarosa, Festival e Oso Grande) as subparcelas, com cinco repetições. Com exceção de 'Oso Grande', adquirida de um viveirista da região de Atibaia-SP, as demais mudas utilizadas eram frigos oriundas da região da Patagônia (Argentina).
'Aromas' é neutra ao fotoperíodo; teve sua origem na Universidade da Califórnia, enquanto 'Camarosa', 'Festival' e 'Oso Grande' são de dias curtos, sendo que a cultivar Camarosa e Oso Grande são também originárias da Universidade da Califórnia, no ano de 1992 e 1987 respectivamente. A cultivar Festival foi desenvolvida na Universidade da Flórida em 1993.

As mudas foram transplantadas para canteiros, em que cada subparcela foi constituída por 15 plantas, sendo acomodadas em três linhas, dispostas no espaçamento de $35 \times 35 \mathrm{~cm}$. Deste total, considerou-se como subparcela útil, as nove plantas centrais, sendo as plantas das duas extremidades mantidas como bordaduras. Deste modo, levando-se em consideração o espaçamento de $40 \mathrm{~cm}$ de um canteiro para outro, ficou definido em 2,53 $\mathrm{m}^{2}$ a área da subparcela e de $203,00 \mathrm{~m}^{2}$, a área total do experimento.

Os tratos culturais e fitossanitários, bem como os demais cuidados com a cultura, foram realizados de acordo com Antunes \& Duarte Filho (2005). Para cada tratamento, levando-se em consideração a época de transplantio, efetuou-se a instalação do mulching de coloração preta, trinta dias após esta operação. Foram também realizadas pulverizações preventivas para o controle fitossanitário e as irrigações realizadas diariamente, via gotejo, tomando-se o cuidado de manter o solo próximo da capacidade de campo.

A colheita foi realizada quando os frutos atingiram $3 / 4$ da sua maturação, sendo colhidos duas vezes por semana, com duração de 4 meses. Assim, com o início das colheitas, foram avaliadas as características de números de frutos totais (NFT), números de frutos comerciais (NFC) e não comerciais (NFNC), massa de frutos totais (MFT), massa de frutos comerciais (MFC) e não comerciais (MFNC).

Para número de frutos totais, foram contabilizados todos os frutos da área útil das subparcelas e para massa de frutos totais os mesmos foram pesados tendo seu valor expresso em gramas. Como forma de seleção de frutos considerados comerciais, para as avaliações de número de frutos e de massa fresca dentro dessa categoria, foi realizada a 
seleção de frutos com base no diâmetro equatorial dos mesmos, sendo que os que apresentaram medida inferior a 15 $\mathrm{mm}$ foram considerados não comerciais (Alvarenga, 2006).

Os dados foram submetidos à análise de variância e as médias comparadas pelo teste de Scott-Knott (1974), ao nível de $5 \%$ de probabilidade, utilizando o programa SISVAR 4.0 (Ferreira, 1999).

\section{RESULTADOS E DISCUSSÃO}

Entre as características avaliadas, com exceção do número e massa de frutos não comerciais, as demais apresentaram efeito significativo da interação entre os fatores época de cultivo e cultivares. As cultivares não diferiram estatisticamente entre si para o número médio de frutos comerciais (Tabela 1), na época de plantio de maio. Para as épocas de plantio de junho e julho, a cultivar Oso Grande foi superior às demais. Ainda, em relação à época de plantio, no mês de agosto o desempenho foi inferior, porem, nesta época 'Oso Grande' e ‘Aromas' apresentaram melhores desempenhos em comparação a 'Festival' e 'Camarosa'. Conduzindo um experimento de abril a novembro em Pouso Alegre-MG, Dias et al. (2009) também encontraram menor número de frutos comerciais da cultivar $\mathrm{Ca}$ marosa, que pode ser atribuído ao tipo de inflorescência bastante ramificada que resulta em maior número de frutos pequenos no final do ciclo.

Antunes et al. (2008), trabalhando com comportamento produtivo de novas cultivares para a região de Pelotas-RS, com plantio no mês de maio, encontraram resultados semelhantes para número de frutos comerciais por planta, para as cultivares Aromas e Camarosa, dados que corroboram com os encontrados neste trabalho. Entretanto para a cultivar Oso Grande, o plantio no mês de agosto proporcionou resultados inferiores às demais.

A menor porcentagem de frutos comerciais observada nas cultivares Camarosa e Festival mostra que, mesmo sendo estas cultivares de dias curtos, como 'Oso Grande', com o aumento do fotoperíodo e da temperatura essas

Tabela 1. Valores médios de número de frutos comerciais por planta, em função das épocas de plantio e cultivares (average number of marketable fruits per plant, depending on planting seasons and cultivars). Lavras, UFLA, 2009.

\begin{tabular}{lccrc}
\hline Época de plantio & Aromas & Camarosa & Festival & Oso Grande \\
\hline Maio & $33,6 \mathrm{aA}$ & $31,44 \mathrm{aA}$ & $36,96 \mathrm{aA}$ & $29,28 \mathrm{aA}$ \\
Junho & $16,2 \mathrm{bB}$ & $15,36 \mathrm{bB}$ & $13,72 \mathrm{bB}$ & $40,68 \mathrm{aA}$ \\
Julho & $21,8 \mathrm{bB}$ & $20,12 \mathrm{bB}$ & $16,24 \mathrm{bB}$ & $29,60 \mathrm{aA}$ \\
Agosto & $15,64 \mathrm{aB}$ & $4,44 \mathrm{cC}$ & $8,75 \mathrm{bC}$ & $16,24 \mathrm{aB}$ \\
\hline
\end{tabular}

CV (\%) 5,50

Médias seguidas de mesma letra minúscula nas linhas e maiúscula na coluna não diferem entre si pelo teste de Scott-Knott, 5\% de probabilidade (averages followed by the same lowercase letters in the lines and uppercase letters in the columns, do not differ among themselves by Scott-Knott test, $5 \%$ probability).

Tabela 2. Valores médios obtidos para massa de frutos comerciais (g/planta) em função das épocas de plantio e cultivares estudadas (average values obtained for marketable fruits ( $\mathrm{g} /$ plant), depending on planting season and cultivar). Lavras, UFLA, 2009.

\begin{tabular}{lcrcr}
\hline Época de plantio & Aromas & Camarosa & Festival & Oso Grande \\
\hline Maio & $582,49 \mathrm{aA}$ & $543,06 \mathrm{aA}$ & $672,05 \mathrm{aA}$ & $536,48 \mathrm{aA}$ \\
Junho & $259,07 \mathrm{bB}$ & $257,27 \mathrm{bB}$ & $243,94 \mathrm{bB}$ & $694,21 \mathrm{aA}$ \\
Julho & $334,64 \mathrm{bB}$ & $359,68 \mathrm{bB}$ & $255,30 \mathrm{bB}$ & $492,99 \mathrm{aA}$ \\
Agosto & $312,07 \mathrm{aB}$ & $78,41 \mathrm{cC}$ & $117,91 \mathrm{bC}$ & $262,33 \mathrm{aB}$ \\
\hline
\end{tabular}

CV (\%) 3,92

Médias seguidas de mesma letra minúscula nas linhas e maiúscula na coluna não diferem entre si pelo teste de Scott-Knott, 5\% de probabilidade(averages followed by the same lowercase letters in the lines and uppercase letters in the columns, do not differ among themselves by Scott-Knott test, $5 \%$ probability).

cultivares não apresentaram desempenho satisfatório. No entanto, no plantio de agosto, o desempenho da cultivar 'Aromas' não diferiu estatisticamente de 'Oso Grande'. Nesse sentido, a 'Oso Grande' tem apresentado maior estabilidade fenotípica na região sul de Minas Gerais.

A cultivar Oso Grande apresentou rendimento superior de massa de frutos comerciais (Tabela 2), quando comparada com as cultivares Camarosa e Festival, nos plantios de junho a agosto e superior a 'Aromas' apenas em junho e julho. Novamente o plantio no mês de maio se destaca apresentando melhor produção de massa de frutos comerciais, para 'Aromas', 'Camarosa' e 'Festival', enquanto 'Oso Grande' foi indiferente ao plantio de maio a julho.

$\mathrm{Na}$ época de plantio de agosto, em termos de massa de frutos comerciais, os desempenhos de 'Aromas' e 'Oso Grande' foram superiores ao de 'Festival', que por sua vez, foi superior ao de
'Camarosa'.

A maior produção de massa de frutos comerciais da cultivar Oso Grande pode ser explicada em virtude de seus frutos serem mais pesados em relação às cultivares Camarosa e Festival nas épocas de plantio de junho, julho e agosto; possivelmente apresenta melhor "performance" genética, talvez justificando a ocupação das áreas plantadas em 90\% com essa cultivar (Castro, 2004).

Para a característica de número de frutos não comerciais, nas épocas de plantio estudas (maio, junho, julho e agosto), os valores obtidos (respectivamente 0,$42 ; 0,33 ; 0,55$ e 0,50$)$ não diferiram entre si. As cultivares Aromas, Oso Grande e Festival apresentaram maiores valores sendo que Festival diferiu das outras duas cultivares. 'Camarosa' apresentou menor número de frutos não comerciais em comparação às outras cultivares utilizadas $(0,29$ frutos/planta). A menor quantidade de 
frutos não comerciais apresentada por essa cultivar provavelmente é decorrência de ter produzido menor número de frutos totais. Uma característica de 'Camarosa' é que geralmente produz frutos maiores devido ao seu grande desenvolvimento vegetativo, mas não apresenta boa adaptabilidade, principalmente em épocas em que a temperatura começa a se elevar. Duarte Filho (2006) mencionou uma produção de frutos não comerciais superior para Oso Grande em relação a Camarosa, corroborando com este trabalho.

Para massa de frutos não comerciais os plantios de maio e julho apresentaram os piores resultados respectivamente 6,53 e 5,77 g planta ${ }^{-1}$. Nos meses de junho, julho e agosto as cvs. se sobressaíram com menor massa de frutos não comerciais, respectivamente 4,77 e 2,50 $\mathrm{g} \mathrm{planta}^{-1}$, sendo considerados os melhores. As cultivares Camarosa e Festival apresentaram menores médias, respectivamente 2,62 e 3,83 g planta $^{-1}$, sendo consideradas assim melhores quando comparadas com as cultivares Aromas e Oso Grande respectivamente 6,69 e 6,43 g planta $^{-1}$.

O fato da 'Camarosa' ter apresentado menor valor para massa de frutos não comerciais pode ser atribuído ao fato de ser uma cultivar que apresenta frutos maiores no início da colheita, e no final resulta um número de frutos menores tendo como consequência uma massa menor, e possivelmente também pode ser atribuído à sua não adaptabilidade a Bom Repouso-MG.

Diante dos resultados obtidos, as produtividades foram representativas nas condições de Bom Repouso, concluindo-se que a melhor época de plantio para 'Aroma', 'Camarosa' e 'Festival foi o mês de maio, enquanto que para 'Oso
Grande' foi maio junho e julho. Para o plantio de maio não houve diferença entre as cultivares. Independente da época de plantio, a cultivar que apresentou melhor resultado foi Oso Grande.

\section{AGRADECIMENTOS}

A CAPES, CNPq e ao IFSULDEMINAS, Campus Inconfidentes, pela liberação dos estudos, ao professor Ademir José Pereira e ao pesquisador Joaquim de Pádua Gonçalves e à empresa GA PEREIRA pela cessão do local do experimento.

\section{REFERÊNCIAS}

ALVARENGA JO. 2006. Classificação, embalagem e rotulagem do morango. In: CARVALHO SP (coord). Boletim de morango: cultivo convencional, segurança alimentar e cultivo orgânico. Belo Horizonte: FAEMG, p. 119-126.

ANTUNES LEC; DUARTE FILHO J. 2005. Importância do cultivo. In: Sistema de produção, 5. Pelotas: Embrapa Clima Temperado. Disponível em: http://sistemasdeproducao. cnptia.embrapa.br/FontesHTML/Morango/ SistemaProducaoMorango/index.htm. Acessado em 21 de agosto de 2010.

ANTUNES LEC; DUARTE FILHO JD; CALEGARIO FF; COSTA H; REISSER JUNIOR C. 2007. Produção integrada de morango (PIMo) no Brasil. In: Morango: conquistando novas fronteiras. Informe Agropecuário 28: 34-39.

ANTUNES LEC; RISTOW NC; KROLOW ACR; CAPENEDO S; REISSER JÚNIOR C. 2008. Comportamento produtivo de novas cultivares de morangueiro na região de Pelotas, $R S$. Pelotas: Embrapa Clima Temperado. 20 p.(Boletim de pesquisa e Desenvolvimento, 70).

ASSIS M. 2004. Produção de matrizes e mudas de morangueiro no Brasil. In: Simpósio Nacional do Morango, 2, 2004, Pelotas. Anais... Pelotas: Embrapa Clima Temperado, p. 45-50.

BERNARDINI J; HOFFMANN A; PALOMBINI MC; ANTUNES LEC; CALGARO A; PASA J; FREIRE JM. 2005. Sistema de produção de morango para mesa na região da Serra Gaúcha e encosta superior do Nordeste. Embrapa Uva e Vinho. Disponível em http:// sistemasdeproducao.cnptia.embrapa.br/ FontesHTML / Morango/MesaSerraGaucha/ plantio.htm. Acessado em 29 de agosto de 2012.

BOTELHO JS. 1999. Situação atual da cultura do morangueiro no estado de Minas Gerais. In: Informe Agropecuário 20: 22-23.

CASTRO RL. 2004. Melhoramento genético do morangueiro: avanços no Brasil. In: Simpósio Nacional do Morango, 2. PelotasRS, p. 22. Disponível em: http://www. cpact.embrapa.br/publicacoes/download/ documentos/documento124.pdf. Acessado em 29 de agosto de 2012.

DIAS JPT; DUARTE FILHO J; PÁDUA JG; CARMO EL. 2009. Desempenho produtivo da cultivar Palomar nas condições de Pouso Alegre-MG. Horticultura Brasileira 27: S2318-S2322.

DUARTE FILHO J. 2006. Cultivares de morango. In: CARVALHO SP (coord). Boletim do morango: cultivo convencional, segurança alimentar, cultivo orgânico. Belo Horizonte: FAEMG, $160 \mathrm{p}$.

FERREIRA DF. 1999. SisVar: sistema de análise de variância para dados balanceados, versão 4.0. Lavras: DEX/UFLA. (Software estatístico).

FILGUEIRA FAR. 2000. Novo Manual de Olericultura: agrotecnologia moderna na produção e comercialização de hortaliças. Viçosa: UFV.

REBELO JA; BALARDIN RSA. 1997. Cultura do morangueiro. $3^{\mathrm{a}}$ edição. Florianópolis: EPAGRI. 44 p.(Boletim Técnico 46).

RIBEIRO AC; GUIMARÃES PTG; ALVAREZ VH. 1999. Recomendações para o uso de corretivos e fertilizantes em Minas Gerais: $5^{\circ}$ aproximação. Viçosa, $359 \mathrm{p}$.

SCICCO C. 2010. Morango deve ter novo aumento. Jornal Entreposto.com.br. Disponível em http://www.jornalentreposto.com.br/ agricola/hortifruti/1006-safra-de-morangoem-minas-deve-ter-novo-aumento. Acessado em 29 de agosto de 2012.

SCOTT AJ; KNOTT MA. 1974. A cluster analysis method for grouping means in the analysis of variance. Biometrics 30: 507-512.

VEIGA JUNIOR WG. 2006. O morango e sua evolução comercial. In: CARVALHO SP (coord). Boletim de morango: cultivo convencional, segurança alimentar e cultivo orgânico. Belo Horizonte: FAEMG, 119-126. 